\title{
Enhanced immunogenicity of leukemia-derived exosomes via transfection with lentiviral vectors encoding costimulatory molecules
}

\author{
Weiwei Hu ${ }^{1} \cdot$ Fang Huang ${ }^{1} \cdot$ Liuxin $\mathrm{Ning}^{1} \cdot$ Jun $\mathrm{Hao}^{2,3} \cdot$ Jiangbo Wan $^{1} \cdot$ Siguo Hao ${ }^{1}$ (D)
}

Accepted: 15 May 2020 / Published online: 23 June 2020

(C) The Author(s) 2020

\begin{abstract}
Background: Tumor cell-derived exosomes (TEXs) have been widely used to induce antitumor immune responses in animal models and clinical trials. Similarly, leukemia cell-derived exosomes (LEXs) can induce antileukemia immune responses in animal models. However, the antileukemia immunity induced by LEXs is less effective, which may be due to an inadequate costimulatory capacity.

Methods: In this study, we transduced L1210 leukemia cells with a lentiviral vector encoding two B7 costimulatory molecules (CD80, CD86) and obtained LEXs that highly expressed CD80 and CD86. The antileukemia immune response derived from these LEXs was examined in vitro and in vivo in animal models.

Results: We found that B7 gene-modified LEXs, including LEX-CD80, LEX-CD86, and LEX-8086, could significantly boost the expression of CD80 and CD86 in dendritic cells (DCs) and promote the secretion of functional cytokines such as TNF- $\alpha$ and IL-12. Moreover, these B7 gene-modified LEXs, particularly LEX-CD8086, could effectively induce $\mathrm{CD} 4^{+} \mathrm{T}$ cell proliferation, Th1 cytokine secretion, and an antigen-specific anti-leukemia cytotoxic T lymphocyte (CTL) response. Additional animal studies indicated that immunization with B7 gene-modified LEXs, in particular LEX-CD8086, could significantly retard tumor growth compared to the control LEXnull group.

Conclusions: This study sheds light on the feasibility of obtaining LEXs that overexpress costimulatory molecules via genetically modified leukemia cells, thereby enhancing their anti-leukemia immunity and providing a potential therapeutic strategy that contributes to leukemia immunotherapy.
\end{abstract}

Keywords Leukemia $\cdot$ Exosomes $\cdot$ Costimulatory molecules $\cdot$ Immunotherapy

$\begin{array}{ll}\text { Abbreviations } \\ \text { DC } & \text { Dendritic cell } \\ \text { TEX } & \text { Tumor-derived exosome } \\ \text { LEX } & \text { Leukemia-derived exosome }\end{array}$

Siguo Hao

haosiguo@xinhuamed.com.cn

1 Department of Hematology, Xinhua Hospital Affiliated to Shanghai Jiaotong University School of Medicine, 1665\# Kongjiang Road, Shanghai 200090, China

2 Interdisciplinary Oncology Program, Faculty of Medicine, University of British Columbia, Vancouver, BC, Canada

3 Department of Experimental Therapeutics, BC Cancer Agency, Vancouver, BC, Canada

$\begin{array}{ll}\text { HSP } & \text { Heat shock protein } \\ \text { IL-2 } & \text { Interleukin } 2 \\ \text { TGF- } \beta 1 & \text { Transformation growth factor-1 } \\ \text { TNF- } \alpha & \text { Tumor necrosis factor- } \alpha \\ \text { IFN- } \gamma & \text { Interferon- } \gamma \\ \text { CTL } & \text { Cytotoxic T lymphocyte } \\ \text { APC } & \text { Antigen-presenting cell } \\ \text { CTLA-4 } & \text { Cytotoxic T lymphocyte-associated protein } 4\end{array}$

\section{Introduction}

Recently, remarkable progresses have been made in the clinical treatment of leukemia, and these are mainly attributed to high doses of chemotherapy and hematopoietic stem cell transplantation $[1,2]$. However, several patients, especially the elderly, still suffer and cannot benefit from these strategies [3]. Therefore, novel and tolerable treatments for leukemia are 
urgently needed. Immunotherapy has revolutionized leukemia therapy in the past few years by, for instance, using chimeric antigen receptor T cell (CAR-T) therapy [4] or immune checkpoint inhibitors, which are two successful therapeutic strategies in this field [5-9]. Additionally, the use of anti-tumor vaccines represents another remarkable type of immune therapy which inhibits leukemia relapse and promotes leukemiafree survival $[10,11]$.

Previously we found, along with others, that most tumor cells secrete exosomes and that tumor cell-derived exosomes (TEXs) are highly enriched in tumor-associated antigens as well as in a series of immune-related proteins such as histocompatibility complex molecules and heat shock proteins [12-16]. Therefore, TEXs are considered as promising antitumor vaccines. Like tumor cells, leukemia cells also release exosomes. These leukemia cell-derived exosomes (LEXs) may harbor leukemia cell-associated antigens that can induce anti-leukemia immunity in vitro and in vivo $[17,18]$. However, the anti-leukemia immunity induced by LEXs is still less effective, which may mainly result from an inadequate costimulatory capacity [19]. Therefore, LEX-based antileukemia vaccines still need to be optimized in order to improve their immunogenicity. Some studies have used vectors encoding B7-1 (CD80), ICAM-1, and LFA-3 to efficiently overexpress these costimulatory molecules in dendritic cells (DCs) and leukemia cells, after which an increased antigenpresenting potency of these cells was observed compared to their uninfected counterparts, as demonstrated by enhanced $\mathrm{T}$ cell responses [20, 21]. Another study showed that enhanced immunogenicity targeting chronic lymphocytic leukemia (CLL) cells could be obtained via transfection with vectors encoding multiple costimulatory molecules [22]. Based on these observations, we hypothesized that a high expression of costimulatory molecules on LEXs may enhance the antileukemia immunity of LEX-based vaccines.

B7 proteins, including B7-1 (CD80) and B7-2 (CD86), are classical costimulatory molecules that are expressed on the surface of antigen-presenting cells (APCs). They can interact with the co-receptor CD28, which is constitutively expressed on the surface of both naive and activated $\mathrm{CD} 4^{+} \mathrm{T}$ cells. It has been found that cytotoxic $\mathrm{T}$ cells better eradicated murine malignancies when transfected to express CD80 and CD86, thus demonstrating a role of $\mathrm{B} 7$ proteins in antitumor immunity [23]. A previous report also demonstrated that antigen presentation by malignant blood cells for the activation of cytotoxic $\mathrm{T}$ cells could be strengthened through CD80 cDNA transfection [24], whereas others modified DCs by RNA interference targeting CD80 and CD86 leading to a low $\mathrm{T}$ cell responsiveness via enhanced $\mathrm{T}$ cell apoptosis [25].

In this study, CD80 and CD86 were overexpressed in L1210 leukemia cells through transduction of lentiviruses encoding CD80 and CD86. LEXs were purified from the supernatants of the transfected cells. We found that transduced leukemia cell-derived LEXs (LEX-CD80, LEX-CD86, LEXCD8086) carried ectopic levels of CD80 and CD86. These B7 gene-modified LEXs could efficiently promote $\mathrm{CD} 4^{+} \mathrm{T}$ cell proliferation, stimulate Type I cytokine secretion, and induce an antigen-specific anti-leukemia cytotoxic $\mathrm{T}$ lymphocyte (CTL) response, leading to a stronger anti-leukemia protective immunity in vivo.

\section{Materials and methods}

\subsection{Reagents}

RPMI-1640 medium, fetal bovine serum (FBS), and serumfree medium were all purchased from Invitrogen (Shanghai, China). Rabbit anti-mouse hsp70, CD9, CD63, and CD81 antibodies were purchased from Cell Signaling Technology (Shanghai, China). Recombinant mouse granulocytemacrophage colony-stimulating factor (rmGM-CSF), recombinant mouse interleukin rmIL-4, rmIL-2, and lipopolysaccharide (LPS) were purchased from PeproTech (Shanghai, China). PE-labeled anti-CD11c, PE-cyanine7 conjugated anti-CD80, and APC-labeled anti-CD86 were purchased from eBioscience (Shanghai, China). EasySep ${ }^{\mathrm{TM}}$ Mouse $\mathrm{CD} 4^{+}$ and $\mathrm{CD} 8^{+} \mathrm{T}$ cell isolation kits were purchased from Stem Cell Technologies (Vancouver, Canada).

\subsection{Cell lines and animals}

L1210, an acute lymphoblastic leukemia cell line from DBA/2 mice, was purchased from the Chinese Academy of Sciences (Shanghai, China). In order to avoid the influence of FBS exosomes, L1210 cells were cultured in RPMI-1640 medium containing 10\% exosome-free FBS, $100 \mu \mathrm{g} / \mathrm{ml}$ penicillin, and $100 \mathrm{mg} / \mathrm{ml}$ streptomycin at $37{ }^{\circ} \mathrm{C}$ in a sterile incubator containing $5 \% \mathrm{CO}_{2}$. Six to eight-week-old DBA/2 female mice were purchased from the Shanghai SLAC Laboratory Animal Center (Shanghai, China) and kept under standard specificpathogen-free (SPF) conditions. All animal experiments were conducted according to the guidelines of the Ethics Committee of Xinhua Hospital, affiliated to the Shanghai Jiao Tong University School of Medicine, Shanghai, China.

\subsection{Lentivirus vector construction}

Two self-complementary oligonucleotide pairs carrying sequences that target mouse CD80 and CD86 were designed and synthesized (Shanghai Hanbio Co., Ltd., Shanghai, China). The CD80 and CD86 paired oligonucleotides were separately ligated into lentiviral frame plasmids. The recombinant plasmids were transformed into Escherichia coli cells 
and positive clones were selected by PCR. 293T cells were cotransfected with the recombinant lentiviral vectors $(1.7 \mu \mathrm{g})$, pSPAX2 vector $(1.13 \mu \mathrm{g})$, and pMD2G vector $(0.57 \mu \mathrm{g})$ in order to produce lentivirus particles. $72 \mathrm{~h}$ after transfection, supernatants containing lentiviral particles were harvested, filtered through a $0.45-\mu \mathrm{m}$ membrane, and concentrated via ultracentrifugation. The lentiviral vectors expressed the green fluorescence and anti-puromycin proteins. Fluorescence intensity and anti-puromycin screening tests were used to ensure virus titration and lentiviral infection efficiency measurements. CD80 and CD86 interference efficiencies were assayed by RT-qPCR and flow cytometry. The CD80 sequences that were used were as follows: forward strand: AGCTGTGACCGGCGCCTACATGGCTTGCAATT GTCAGTTG; reverse strand: TTCCTCTGCCCTCA GCGGCCAAGGAAG ACGGTCTGTTCAGC. The CD86 sequences were as follows: forward strand: ATGGACCC CAGATGCACCAT; reverse strand: TCACTCTGCATTTG GTTTTG.

\subsection{Transduction of leukemia cells and isolation of exosomes}

L1210 cells were pre-cultured in complete medium containing $10 \%$ exosome-free FBS for $24 \mathrm{~h}$ in order to avoid contamination from the serum. L1210 cells were transduced with recombinant lentiviral vectors encoding CD80 and CD86 for $72 \mathrm{~h}$, after which the culture supernatants were collected for the isolation of exosomes as reported previously [26]. Exosomes that were derived from non-manipulated L1210 cells were named control LEX, while exosomes that were purified from the supernatants of L1210 cells transduced with the lentiviral vectors carrying CD80, CD86 or both were named LEXCD80, LEX-CD86, and LEX-CD8086, respectively. LEXs purified from the supernatant of L1210 cells transduced with a null vector were named LEXnull.

\subsection{Flow cytometry}

To quantify the expression of CD80 and CD86 in LEXs, $30 \mu \mathrm{g}$ of LEX preparations were incubated with aldehyde/ sulfate latex beads (Invitrogen, Shanghai, China) at $4{ }^{\circ} \mathrm{C}$ overnight. Next, $100 \mathrm{mmol} / \mathrm{L}$ glycine was added to block the reaction. The exosome-loaded beads were washed twice in PBS buffer containing 1\% FBS and then stained with specific antibodies directed against mouse CD80 and CD86 or the isotype control. Subsequently, the prepared samples were analyzed using a FACScan. In order to analyze DC phenotypes, the cells were concentrated, washed with PBS twice, and next incubated with fluorescent-conjugated monoclonal antibodies (mAb) directed against CD80, CD86, and CD11c for $30 \mathrm{~min}$ at room temperature.

\subsection{Electron microscopic and Western blot analyses of exosomes}

Exosome samples were stained according to negative staining procedures and the morphology of exosome preparations was visualized using a Philips CM12 transmission electron microscope operating at $80 \mathrm{kV}$. Western blot analysis of the typical exosome markers CD9, CD63, and Hsp70 was conducted as previously described [27]. The primary antibodies used were all purchased from Cell Signaling Technology (Shanghai, China). Exosomes were enriched at high concentrations for an efficient protein extraction and the results were analyzed using Image Lab software.

\subsection{Cytokine assay}

Tumor necrosis factor- $\alpha$ (TNF- $\alpha)$ and IL-12 levels in DC supernatants (48 $\mathrm{h}$ after coculture with LEXs), as well as IFN- $\gamma$, TNF- $\alpha$ and IL-2 levels in CD4 ${ }^{+} \mathrm{T}$ cell supernatants (48 $\mathrm{h}$ after stimulation) were detected using ELISA kits according to the manufacturer's instructions (Westang, Shanghai, China).

\section{8 $\mathrm{CD}^{+} \mathrm{T}$ cell proliferation assay}

Splenic $\mathrm{CD}^{+} \mathrm{T}$ cells of mice immunized with LEX-CD80, LEX-CD86, and LEX-CD8086 were isolated 7 days after the last immunization using an EasySep ${ }^{\mathrm{TM}}$ mouse $\mathrm{CD} 4^{+} \mathrm{T}$ cell isolation kit according to the manufacturer's instructions (Stem-cell Technologies, Vancouver, Canada). Next, the purified CD4 ${ }^{+} \mathrm{T}$ cells $\left(1 \times 10^{5} /\right.$ well $)$ were co-cultured with irradiated L1210 cells $\left(1 \times 10^{4} /\right.$ well $)$ or with $\mathrm{p} 388$ cells $\left(1 \times 10^{4} /\right.$ well $)$ as a control target for $72 \mathrm{~h}$ with $20 \mu \mathrm{g} / \mathrm{ml}$ phytohemagglutinin (PHA) at $37^{\circ} \mathrm{C}$ and $5 \% \mathrm{CO}_{2} .\left[{ }^{3} \mathrm{H}\right]$ thymidine $(0.5 \mu \mathrm{Ci} /$ well $)$ was then added to the medium after which incubation was carried out for $16 \mathrm{~h}$. Subsequently, the cells were harvested and ${ }^{3} \mathrm{H}$-thymidine incorporation was measured by liquid scintillation spectroscopy using a MicroBeta counter (Beckman Coulter, Krefeld, Germany). The results are reported as mean counts per minute (cpm) and the standard error of the mean (SEM). All assays were conducted in triplicate.

\subsection{Cytotoxicity assay}

Cytotoxic responses were evaluated according to the manufacturer's instructions (Promega, Madison, WI, USA). Briefly, splenic $\mathrm{CD}^{+} \mathrm{T}$ cells were isolated from mice immunized with PBS or with $10 \mu \mathrm{g}$ LEX-CD80, LEX-CD86, LEXCD8086 or LEXnull. Seven days after the last stimulation, splenic $\mathrm{CD}^{+} \mathrm{T}$ cells were isolated from immunized mice using an EasySep ${ }^{\mathrm{TM}}$ mouse $\mathrm{CD}^{+} \mathrm{T}$ cell Isolation Kit (Stemcell Technologies, Vancouver, Canada). Cells were restimulated with irradiated L1210 cells for 7 days and then harvested as effector cells. L1210 cells were used as specific 
target cells and p388 cells were used as controls. The cells were seeded in a 96-well plate at $1 \times 10^{4}$ cells/well. After adding CytoTox $96^{\circledR}$ Reagent (Promega, Madison, WI, USA), absorbance at $490 \mathrm{~nm}$ was recorded and cells were incubated for $30 \mathrm{~min}$, protected from light. The magnitude of the cytotoxic response at different effector/target (E/T) ratios was evaluated using a LDH assay (Promega, Madison, WI, USA), and specific lysis (\%) was calculated as follows: (experimental LDH release - effector cells - target spontaneous LDH release)/(target maximum LDH release) $\times 100$ [28]

\subsection{Animal studies}

To evaluate the protective immunity of costimulatory molecule gene-modified LEXs, PBS or $10 \mu \mathrm{g}$ LEX-CD80, LEX-CD86, LEX-CD8086 or LEXnull were subcutaneously (s.c.) injected at the inner side of the right hind thighs of DBA/2 mice on day 0 . The immunization was boosted twice, on day 7 and day 14. On day 21, the immunized mice were s.c. challenged with L1210 cells $\left(0.5 \times 10^{6}\right.$ cells/mouse $)$ at the outer side of the same lateral thighs. Survival rates and tumor sizes (calculated as length $\times$ width $^{2} \mathrm{x} \pi / 6$ ) were assessed every 2 days [28].

\subsection{Generation of bone marrow-derived DCs and coculture with LEXs}

To investigate the effect of B7 gene-modified LEXs on the biologic properties of DCs, we examined the immunophenotype and the secretion of cytokines by DCs cocultured with LEXs. The generation of bone marrowderived DCs from DBA/2 mice has been reported before [29]. Following cell culture for 6 days, DCs were collected and cocultured with the above mentioned LEXs in complete medium containing $10 \%$ exosome-free FBS for $24 \mathrm{~h}$. DCs cultured with LPS or without stimulation were used as controls. DCs and supernatants were collected and stored.

\subsection{Statistical analysis}

Experiments were performed at least three times. Data are presented as the mean \pm SD or SEM. The log-rank test was used to analyze survival data and differences between the two groups were analyzed with Student's $t$ test. Statistical significance was determined as $p<0.05$.

\section{Results}

\subsection{LEXs highly expressing CD80 and CD86 can be obtained from B7 gene-modified L1210 leukemia cells}

To confirm whether LEXs highly expressing CD80 and CD86 could be obtained from the $\mathrm{B} 7$ gene-modified leukemia cells,
L1210 leukemia cells were transduced with lentiviral vectors carrying either B7-1 (CD80) or B7-2 (CD86), or the two genes. As shown in Fig. 1, after transduction, CD80 and CD86 expression in L1210 cells was markedly increased (Fig. 1a, b), particularly when cells were transduced with the two genes (Fig. 1c). The levels of CD80 and CD86 in LEXs derived from transduced cells were detected by flow cytometry to examine whether LEXs derived from B7 gene-transduced cells also express high levels of CD80 and CD86. As shown in Fig. 2, the expression of CD80 in LEX-CD80 and of CD86 in LEX-CD86 were significantly higher than those in LEXnull, indicating that LEXs derived from CD80- and CD86overexpressing cells also overexpress CD80 and CD86. To examine whether gene transduction would affect the biology of LEXs, we examined LEXs derived from modified L1210 cells regarding morphology and the expression of related proteins using electron microscopy and Western blot analysis. As shown in Fig. 2a and b, LEXs exhibited diameters ranging from 40 to $100 \mathrm{~nm}$ and a plate-shaped characteristic morphology. Western blot analysis indicated that all the LEXs derived from B7 gene-modified L1210 cells fully expressed Hsp70, CD9, CD63, and CD81, which are considered typical exosomal proteins. Meanwhile, the expression of CD80 and CD86 on the modified LEXs was confirmed by flow cytometry (Fig. 2c). Together, these data suggest that B7 gene transfection did not affect the biological properties of exosomes derived from transfected leukemia cells.

\subsection{B7 gene-modified LEXs can promote CD4 ${ }^{+} \mathrm{T}$ cell proliferation and induce a potent antigen-specific anti-leukemic CTL response}

$\mathrm{CD}^{+} \mathrm{T}$ cells play a pivotal role in antitumor immune responses. To investigate the antigen-specific $\mathrm{CD}^{+} \mathrm{T}$ cell response induced by modified LEXs, splenic $\mathrm{CD} 4^{+} \mathrm{T}$ cells from mice immunized with LEX-CD80, LEX-CD86, LEXCD8086 and LEXnull were isolated and evaluated for their response to L1210 or p388 cells in vitro. We found that immunization with LEX-CD80, LEX-CD86, LEX-CD8086 and LEXnull induced a certain $\mathrm{CD}^{+} \mathrm{T}$ cell proliferation response to L1210 cells and not any response to p388 cells (Fig. 3a). Among them, the immunization with LEX-CD80, LEX-CD86 and LEX-CD8086 more significantly boosted $\mathrm{CD}^{+} \mathrm{T}$ cell proliferation compared to that with LEXnull $(p<0.05)$. As expected, the strongest $\mathrm{CD} 4^{+} \mathrm{T}$ cell proliferation was obtained in mice immunized with LEX-CD8086 $(p<0.01)$. Furthermore, the levels of IFN- $\gamma$ and IL-2, which are recognized as indicators of a Th1 response, were measured in the $\mathrm{CD}^{+}{ }^{+} \mathrm{T}$ cell culture supernatants. We found that upon stimulation with inactivated $\mathrm{L} 1210$ cells, the splenic $\mathrm{CD} 4^{+} \mathrm{T}$ cells from mice immunized with LEX-CD80 LEX-CD86, and LEX-CD8086 produced higher levels of IFN- $\gamma(76.13 \pm$ $3.35,77.12 \pm 3.57$ and $116.75 \pm 8.97 \mathrm{pg} / \mathrm{ml}$, respectively) 
Fig. 1 Immunophenotype analysis of B7 gene modifiedL1210 cells. (a) Unmodified L1210 cells. (b) L1210 cells transfected with lentiviral vectors carrying CD80 or CD86 genes. (c) L1210 cells transfected with lentiviral vectors carrying both CD80 and CD86 genes. Data are representative of three independent experiments
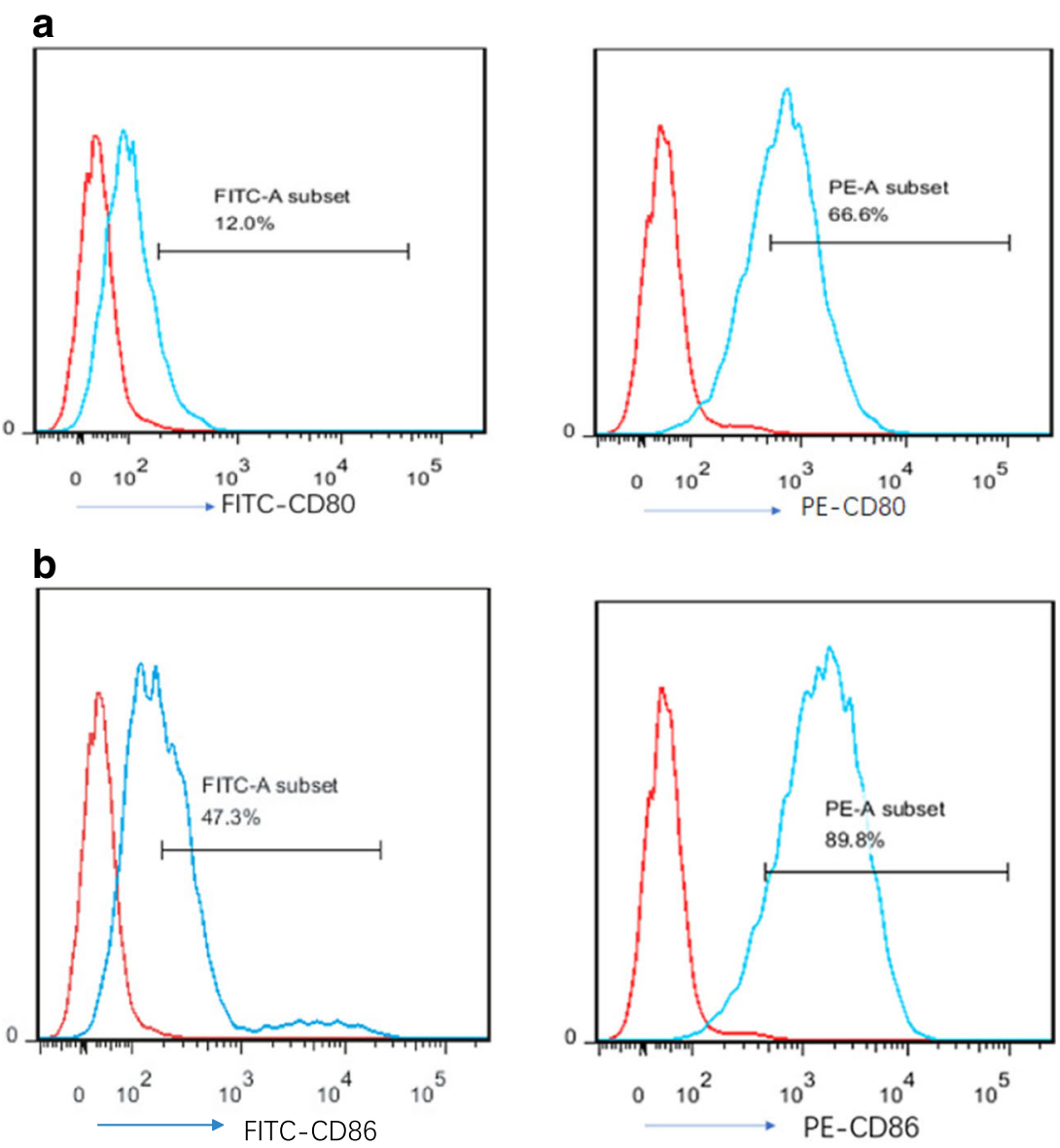

C
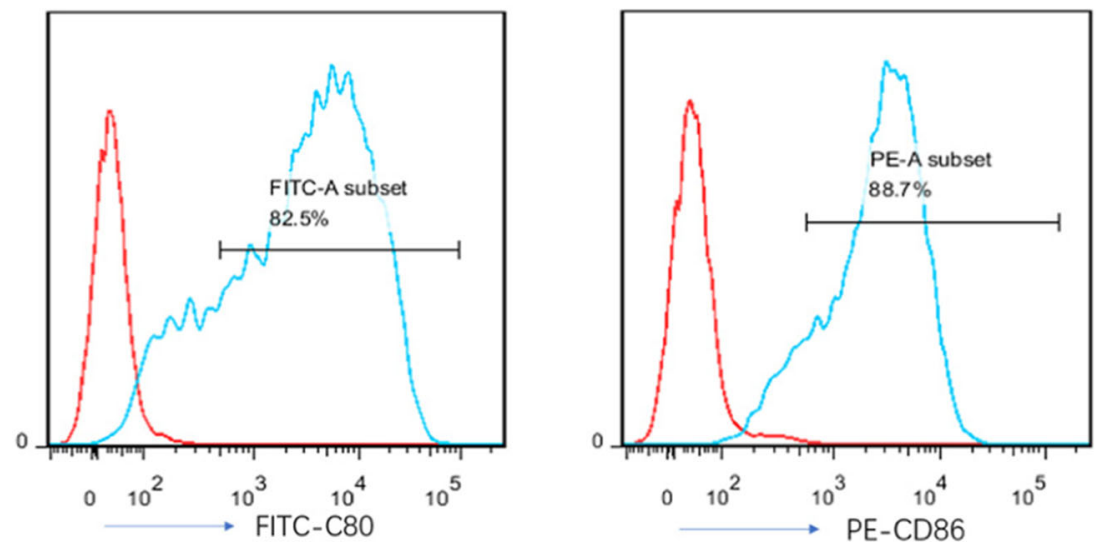

and IL-2 $(64.81 \pm 3.76,69.62 \pm 3.42$ and $92.15 \pm 8.57 \mathrm{pg} / \mathrm{ml}$, respectively) compared to those from mice immunized with LEXnull $(45.36 \pm 5.37$ and $56.60 \pm 4.36 \mathrm{pg} / \mathrm{ml}, p<0.05)$ (Fig. $3 \mathrm{~b}$ and c). As expected, $\mathrm{CD} 4^{+} \mathrm{T}$ cells from mice immunized with LEX-CD8086 produced the highest levels of IFN- $\gamma$ and IL-2 compared to cells from mice in the other groups $(p<0.01)$. Moreover, $\mathrm{p} 388$ cells could stimulate neither the proliferation of, nor the Th1 cytokine secretion by $\mathrm{CD}^{+} \mathrm{T}$ cells, indicating that the $\mathrm{CD} 4^{+} \mathrm{T}$ cell immune response induced by $\mathrm{B} 7$ gene-modified LEXs was antigenspecific.
Next, a cytotoxicity assay was conducted in splenic $\mathrm{CD}^{+} \mathrm{T}$ cells that were isolated from the aforementioned immunized mice to verify whether the modified LEXs exhibit a potential activity on $\mathrm{CD} 8^{+} \mathrm{T}$ cell priming and induce antileukemia cytotoxicity. We found that immunization with the modified LEXs could induce a CTL response against L1210 cells compared to the PBS treatment group (Fig. 3d). The cytotoxic activity at an effector to target $(\mathrm{E} / \mathrm{T})$ ratio of 50:1 in LEX-CD80 $(25.45 \%)$, LEX-CD86 (28.33\%), and LEX-CD8086 $(42.18 \%)$ was stronger than that in the LEXnull group 
Fig. 2 Characterization of LEXs derived from B7 gene modifiedL1210 cells. (a) Exosomes derived from $\mathrm{B} 7$ gene modifiedL1210 cells visualized using electron microscopy. (b) Western blot analysis of typical exosomal proteins. (c) Expression of CD80 and $\mathrm{CD} 86$ on $\mathrm{B} 7$ gene modifiedLEXs measured by flow cytometry. The experiments were performed in triplicate. One representative experiment is shown a

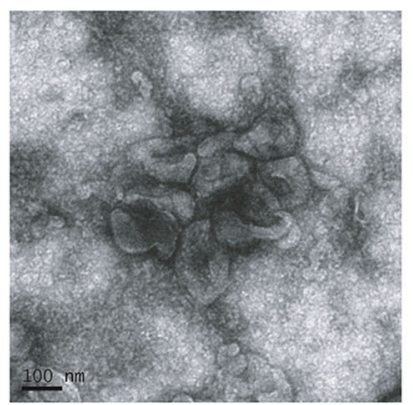

b

HSP70

$\mathrm{CD63}$

CD9

GAPDH - - -

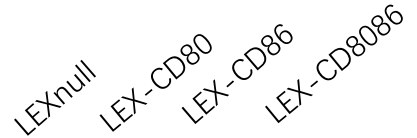

$\mathrm{CD} 81 \div-\cdots$
C

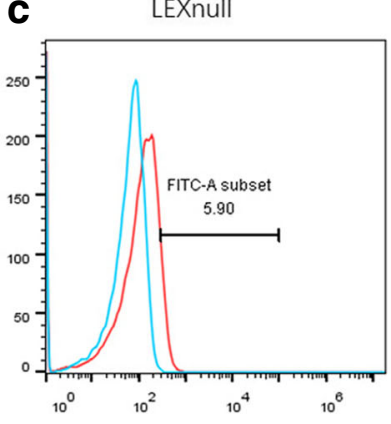

LEXnull

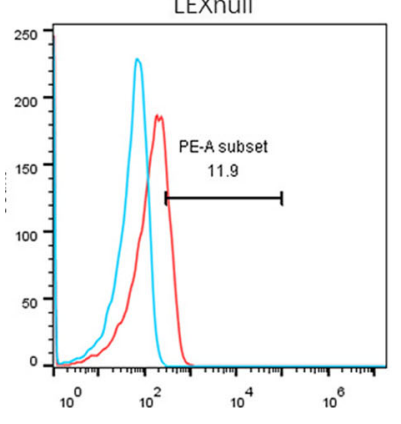

LEX-CD80

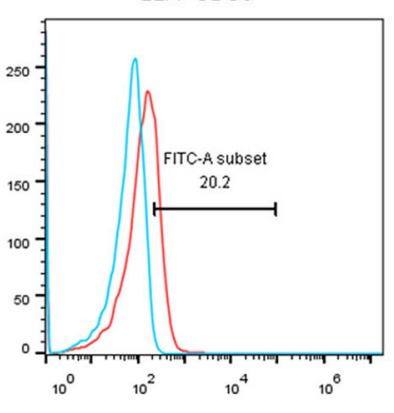

LEX-CD86

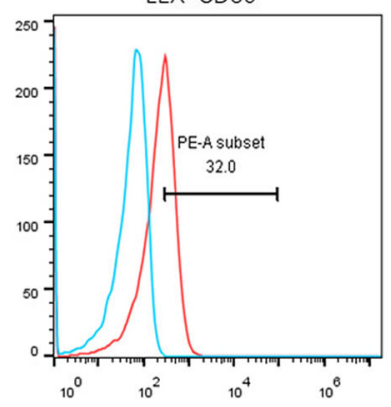

$\longrightarrow$ Fluoresence intensity (Log)
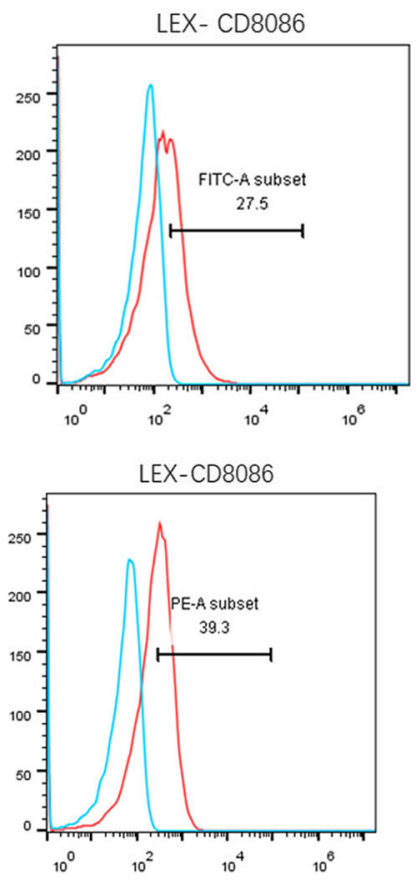

\subsection{B7 gene-modified LEXs induce a stronger protec- tive immunity against leukemia cells}

To investigate protective antileukemia immunity induced by the modified LEXs in vivo, DBA/2 mice were randomized into 5 groups and s.c. pre-inoculated with PBS, LEXnull or with the three types of B7 gene-modified LEXs, twice with a 7-day interval. The mice were subsequently s.c. challenged with $5 \times 10^{5}$ L1210 cells 7 days after the last vaccination. Tumor growth and overall survival were monitored and recorded. We found that tumor growth in mice immunized with LEX-CD80, LEX-CD86, and LEX-CD8086 was significantly retarded compared to that in the PBS and LEXnull groups (Fig. 4). As expected, the slowest tumor growth was 
Fig. $3 \mathrm{CD}^{+} \mathrm{T}$ cell proliferation and cytotoxicity assays. Splenic $\mathrm{CD}^{+} \mathrm{T}$ cells were isolated from immunized DBA/2 mice incubated with irradiated L1210 cells or p388 cells. T cell proliferation was evaluated by ${ }^{3} \mathrm{H}$ thymidine incorporation (a). Secretion of IL2 (b) and IFN- $\gamma(\mathbf{c})$ in culture supernatants was determined by ELISA. $\mathrm{CD}^{+} \mathrm{T}$ cells were isolated from immunized $\mathrm{DBA} / 2$ mice and referred as effectors. L1210 cells served as target cells and cytotoxicity assays were performed at different effector/target cell ratios (d). $* p<0.05$ and $* * p<0.01$ denote statistically significant differences. Data are representative of three independent experiments
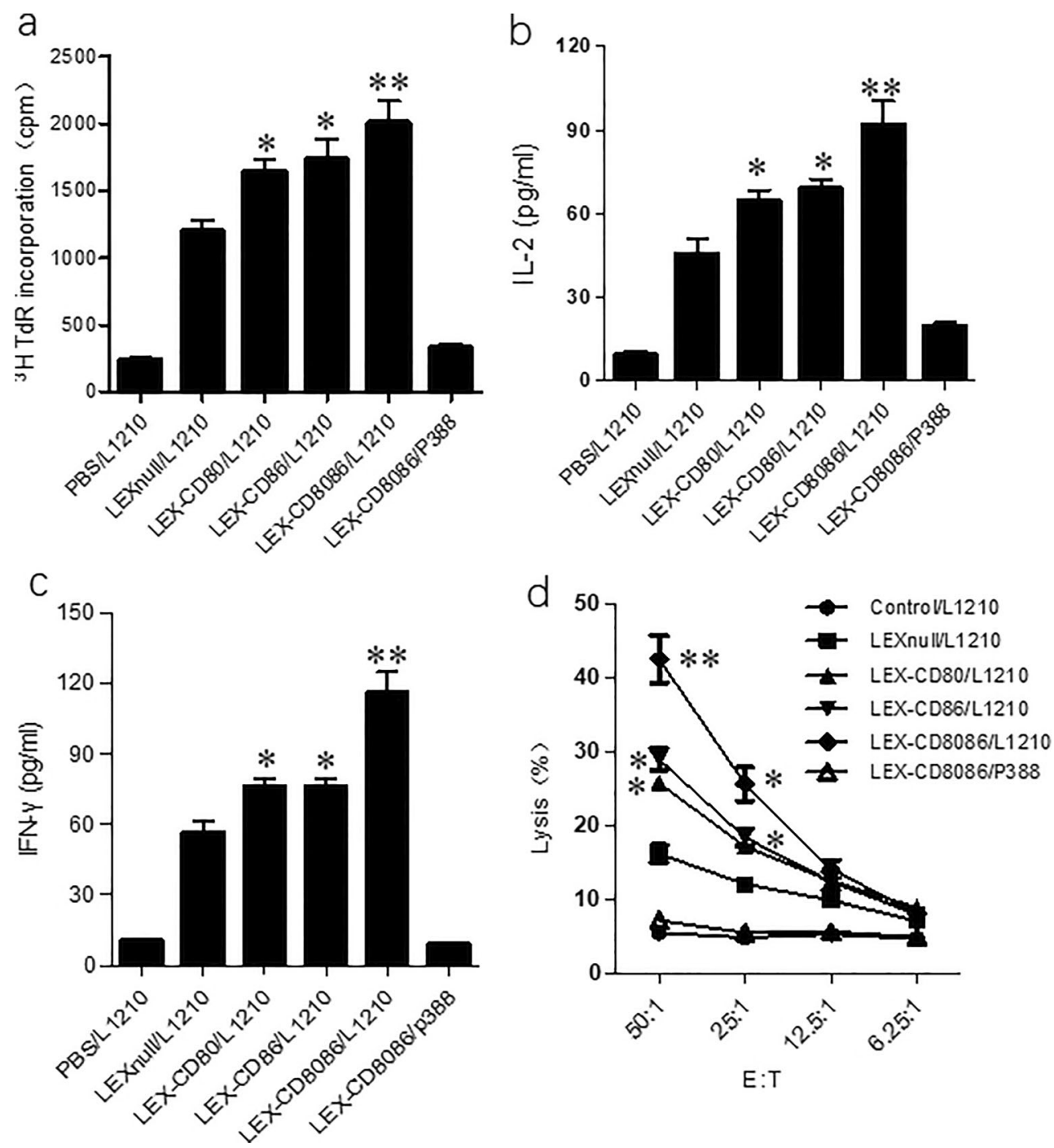

observed in mice immunized with LEX-CD8086, and in some mice the tumors even showed signs of regression (Fig. 4a). Accordingly, the survival of tumor-challenged mice was significantly prolonged by B7 gene-modified LEX vaccination (Fig. 4b). Most mice in the PBS group died approximately 22 days after tumor challenge. The mean survival times (MST) of mice immunized with LEX-CD80 (39 days), LEX-CD86 (40 days), and LEX-CD8086 (49 days) were significantly longer than those of mice immunized with LEXnull (29 days, $p<0.05)$. Two out of ten mice in the LEX-CD 8086 group were alive for more than 60 days after tumor challenge, indicating that the immunization with B7 gene-modified LEXs induced strong antileukemia protective immunity, in particular in the LEX-CD8086 group. In summary, our results indicate that modified LEXs overexpressing CD80 and CD86 can induce a more powerful immunity against leukemia cells.

\subsection{B7 gene-modified LEXs can efficiently promote the maturation of dendritic cells and facilitate their function}

Previously, we found that the immune stimulatory effects of TEXs in vivo depend on the host's DCs and that DCs treated with TEXs could stimulate efficient anti-tumor cytotoxic T lymphocyte responses, since specific tumor antigens that are carried by exosomes can be transferred to DCs $[10,11,24]$. To investigate the mechanism by which B7 gene-modified LEXs induce a stronger antileukemia immunity in vivo, we next set out to examine the effects of modified LEXs on the immunophenotype and secretion of cytokines in DCs. We found that following incubation with the above LEXs for $24 \mathrm{~h}$, the expression levels of CD80, CD86, and CD11c in DCs were markedly elevated compared to the controls (cells incubated with LEXnull or immature DCs) (Fig. 5). The most significant increases were observed when DCs were 

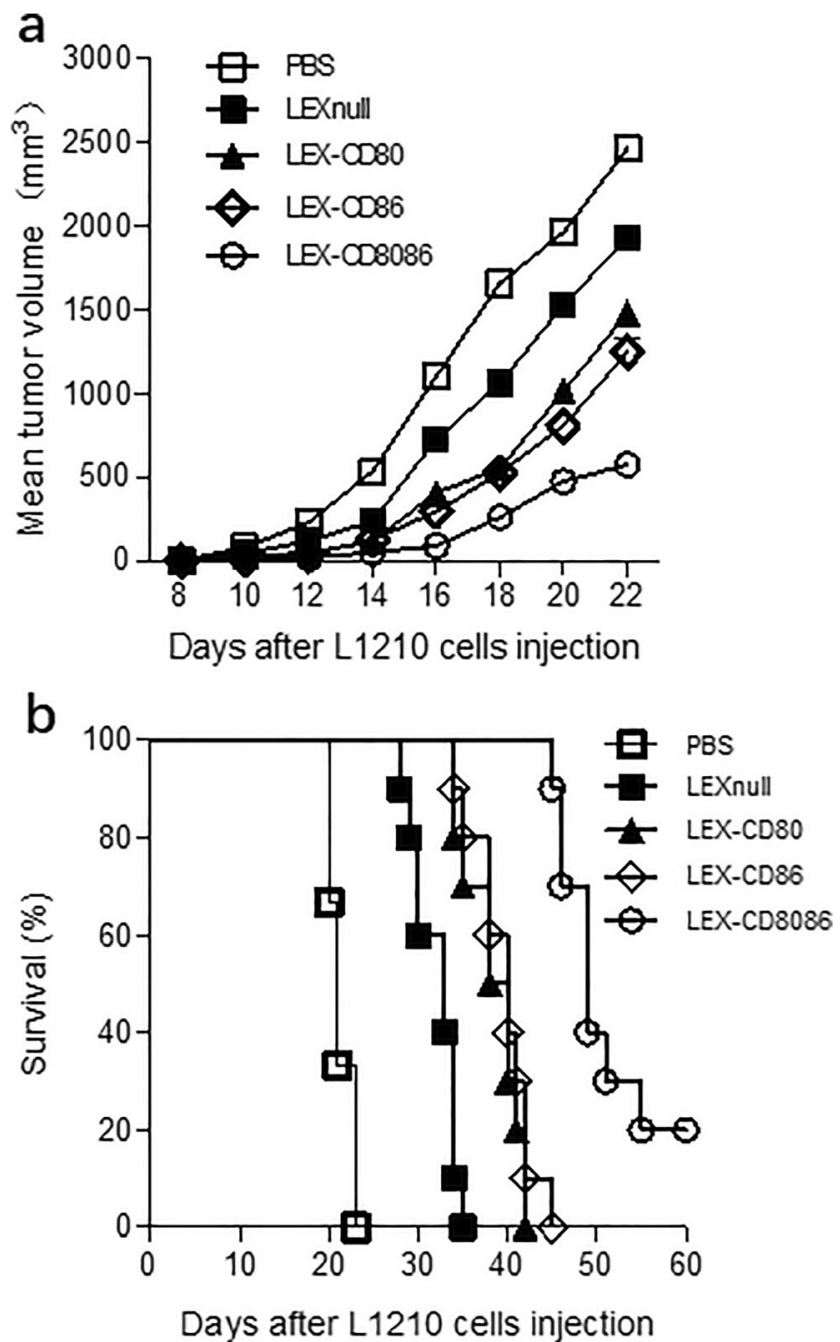

Fig. 4 Immunization with B7 gene modified-LEXs induces antileukemia immunity. DBA/2 mice were s.c. immunized with $10 \mu \mathrm{g}$ of each type of exosome formulation or injected with $100 \mu$ PBS on day 0 , day 7 and day 14 . On day 21 , mice were s.c. challenged with $5 \times$ $10^{5}$ L1210 cells. Each group contained 10 mice. Tumor growth (a) and survival (b) were monitored and recorded after tumor challenge

stimulated with LEX-CD8086 (Fig. 5a). Furthermore, the secretion of both IL-12 and TNF- $\alpha$ in DCs cocultured with LEX-CD80, LEX-CD86, and LEX-CD8086 was also significantly increased compared to that in immature DCs or in cells incubated with LEXnull. As expected, LEX-CD8086 exerted the most significant stimulation, which was even comparable to the effect of LPS (Fig. 5b, $p<0.05$ ). Together, these data suggest that LEXs overexpressing CD80 and CD86 can efficiently promote the phenotypic and functional maturation of dendritic cells, which may be one of the mechanisms through which B7 gene-modified LEXs induce an enhanced antileukemia immune response in vivo.

\section{Discussion}

Although several groups have confirmed the use of TEXs as promising tumor vaccines, the antitumor efficacy of TEXs is still limited [15, 30, 31]. Therefore, improving the efficacy of TEX-based vaccines remains an arduous task. It has been reported that genetically modified tumor cells can be used to develop immunotherapy for leukemia [19, 32]. However, although leukemia cells express leukemia-associated antigens and molecules of the major histocompatibility complexes (MHC) classes I and II, they cannot effectively activate both allogeneic and autologous T cells [33] because they do not sufficiently express costimulatory molecules for T cell activation $[19,22]$. The delivery of a "signal 1 " by antigenpresenting cells (APCs) to the $\mathrm{T}$ cell receptor, in the absence of adequate co-stimulation ("signal 2"), results in T cell anergy and insensitivity to antigen activation. Therefore, upregulation of costimulatory molecules in leukemia cells or APCs is a key issue in the development of leukemia immunotherapy. Several preclinical studies have shown that the introduction of costimulatory molecules in tumor cells enhances their immunogenicity for use as antitumor vaccines [20,34-36]. Among the costimulatory molecules expressed by "professional" APCs, CD80, CD86, and leukocyte function-associated antigen-3 (LFA-3) play key roles in T cell activation $[37,38]$.

In this study, we show that the B7 costimulatory molecules CD80 and CD86 exhibit a low expression on L1210 leukemia cells and its exosomes (LEXs). We hypothesized that this low expression could be the main obstacle for LEX-based vaccines to induce efficient antileukemia immunity, whereas upregulation of the expression of these molecules in leukemia cells or its LEXs could enhance the antileukemia immunity of LEX-based vaccines. Here, we showed that the expression of costimulatory molecules in leukemia cell-derived exosomes could be upregulated through ectopic expression of costimulatory molecule genes in L1210 leukemia cells. These modified LEXs still express CD9, CD63, and HSP70, indicating that this genetic modification did not affect their biological properties. Therefore, we conclude that it is feasible and convenient to artificially modulate the protein composition of exosomes via genetic modification.

$\mathrm{CD} 4^{+}$and $\mathrm{CD} 8^{+} \mathrm{T}$ cells both play unique roles in specific antitumor immunity [39]. Therefore, inducing an effective antigen-specific $\mathrm{CD} 4^{+} \mathrm{T}$ cell and CTL response is the key to LEX-based vaccination. However, TEXs or LEXs alone are not very effective in activating T cells $[15,17,28]$, which may be due to insufficient expression of MHC II and costimulatory molecules, since an increase in costimulatory molecules can enhance the immunogenicity of leukemia cells $[19,22]$. We next evaluated whether elevation of the expression of costimulatory molecules in LEXs could enhance their 
a

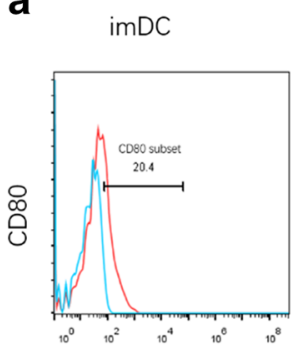

$\mathrm{DC}_{\mathrm{LEX}}$
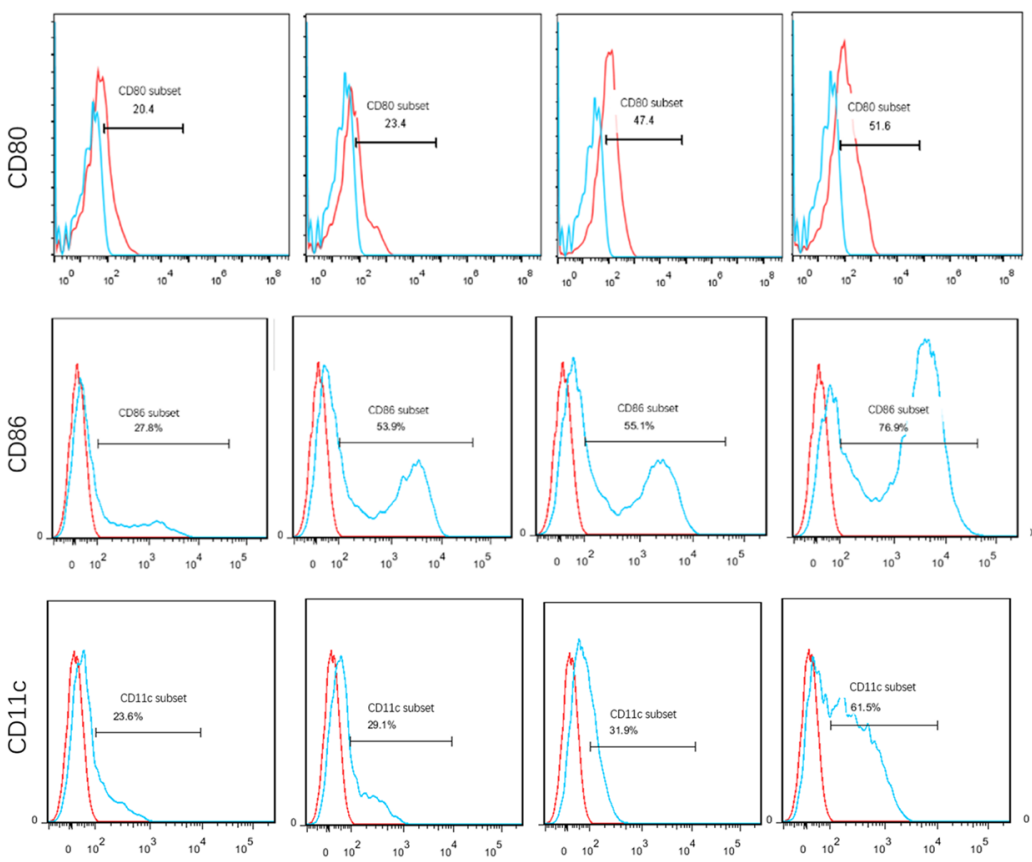

$\mathrm{DC}_{\text {LEX-8086 }}$
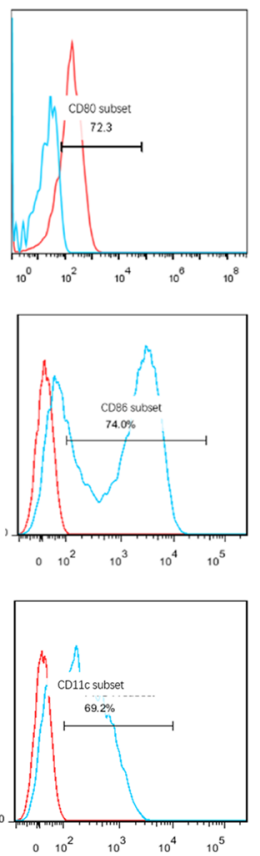

b
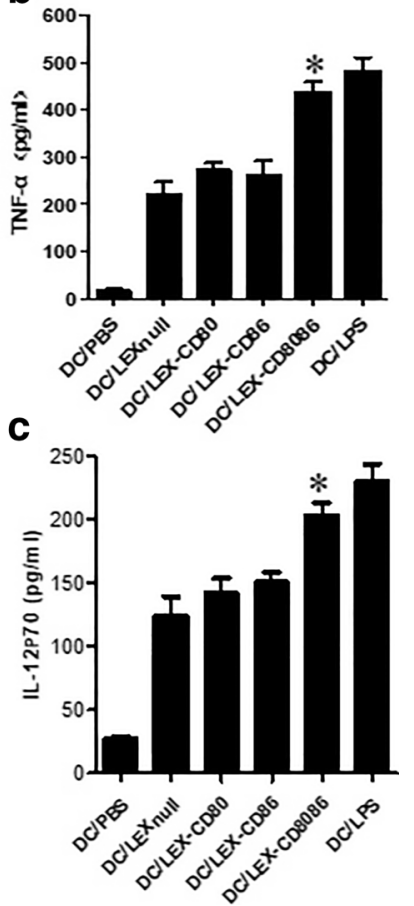

Fig. 5 Effect of B7 gene modified-LEXs on immunophenotype and cytokine secretion of DCs. Immature DCs were incubated for $24 \mathrm{~h}$ with $10 \mu \mathrm{g} / \mathrm{ml}$ LEXnull, LEX-CD80, LEX-CD86 and LEX-CD8086, respectively. Immature DCs in the absence of stimulation were used as negative controls, while LPS-stimulated DCs were used as positive controls.

antileukemia immunity. We found that the $\mathrm{B} 7$ gene-modified LEXs overexpressing CD86 and CD80 efficiently induced $\mathrm{CD}^{+} \mathrm{T}$ cell proliferation and promoted secretion of Th1 cytokines in an antigen-specific manner. Increased Th1 cytokines can potentially induce better CTL responses. Concordantly, we found that leukemia cell antigen-specific CTL activity was most significantly enhanced in mice immunized with the modified LEXs. It has been reported that, despite DC-mediated CTL activation, exosomes are taken up by $\mathrm{CD} 8^{+} \mathrm{T}$ cells and directly induce antigen-specific cytotoxic activity of $\mathrm{CD}^{+} \mathrm{T}$ cells via exosomal MHC molecules [40-42]. Therefore, the enhanced CTL response observed here may be directly mediated by the B7 gene-modified LEXs through overexpression of costimulatory molecules.

To verify if the modified LEXs overexpressing CD86 and CD80 exerted a positive effect on immune cells, we investigated the antileukemia immunity induced by these LEXs in animal models. We found that the modified LEXs showed superiority in inhibiting tumor growth as well as in prolonging survival. These data indicate that costimulatory molecule gene-modified LEXs can more efficiently induce antileukemia immunity compared to non-modified LEXs. Among these modified LEXs, the most efficient stimulatory effect on immune cells, the induction of a CTL response and antileukemia protective immunity in the animal model was
Expression of CD80, CD86 and CD11c on the surface of DCs was determined by flow cytometry (a). The levels of IFN- $\gamma(\mathbf{b})$ and IL-12p70 (c) in DC supernatants were measured by ELISA. ${ }^{*} p<0.05$ denotes statistically significant difference. Data are representative of three independent experiments and expressed as mean \pm SEM

exerted by LEX-CD8086, indicating that an enhanced immunogenicity of LEXs was achieved via infection with vectors encoding multiple costimulatory molecules.

Previous studies have suggested that APCs can capture lipoproteins or tumor cell-associated antigens (TAA) and thus, that the expression of costimulatory molecules and cytokine secretion would be significantly enhanced [43, 44]. CD80 and CD86 are two major costimulatory molecules that play significant roles in $\mathrm{T}$ cell priming for IL- 2 and IFN- $\gamma$ production. Hence, it is reasonable to speculate that overexpression of CD 80 and CD86 may boost the effects of LEXs on the immune system. The majority of mice immunized with B7 gene modified LEXs did, however, not show long-term survival during our observation period, suggesting that the overexpression of costimulatory molecules alone in LEX-based vaccines may still not be sufficient to inhibit tumor progression. Therefore, further optimization of LEX-based vaccines is still required.

We and others have reported that TEXs are predominantly internalized by DCs and directly influence their maturation and function $[15,29,45]$. DCs are major APCs and are responsible for activating both $\mathrm{CD} 4^{+}$and $\mathrm{CD} 8^{+} \mathrm{T}$ cells against tumors [46]. Previously, we also suggested that the immune stimulatory effects of TEXs are dependent on the host's DCs $[15,47]$. Therefore, it remained to be explored whether overexpression of costimulatory molecules in LEXs can enhance 
DC function. We found that similar to other TEXs, B7 gene modified-LEXs can be taken up by DCs (data not shown). Therefore, a LEX-carried antigen profile can be transferred to DCs and may induce antigen-specific antileukemia immunity. Furthermore, we found that coculture with these B7 gene modified-LEXs could markedly elevate the expression of surface costimulatory molecules and promote the secretion of cytokines by DCs, suggesting that the expression of costimulatory molecules in LEXs can enhance the maturation and function of DCs. These results also suggest that overexpression of costimulatory molecules in LEXs may reverse the immune suppressive effect caused by LEX-induced obstruction of DC maturation and activation. Thus, overexpression of costimulatory molecules in LEXs may be effective for boosting DC function and antileukemia immunity.

CD80 and CD86 are double-edged swords, because $\mathrm{CD} 28$ and cytotoxic $\mathrm{T}$ lymphocyte-associated protein 4 (CTLA-4) simultaneously share them. CTLA-4 signaling is crucial for $\mathrm{T}$ cell activation, can decrease the activity of helper $\mathrm{T}$ cells (Th1) and enhance the immunosuppressive activity of regulatory $\mathrm{T}$ cells when combined with CD80 and CD86 [48]. Other immunosuppressive molecules, such as Fas ligand and IL-10 can interfere with the immunogenicity of TEX-based vaccines [48]. Recently, we found that the anti-leukemia immunity of LEXs can be enhanced via silencing or downregulation of TGF- $\beta 1$ expression [31]. Therefore, our next step is to combine the reversal of inhibitory effects of immunosuppressive molecules through silencing or downregulation of TGF- $\beta 1$ with the overexpression of costimulatory molecules in LEX-based vaccines to amplify TCR signaling and activate $\mathrm{T}$ cell proliferation. Overall, our study provides a novel and promising basis for optimizing LEX-based vaccines.

Acknowledgments This research was supported by the National Natural Science Foundation of China (Grant No. 81470314, 81873435).

Author contributions Siguo Hao designed the study. Weiwei Hu and Fang Huang collated the data, carried out data analyses and produced the initial draft of the manuscript. Ning Liuxin, Jun Hao and Jiangbo Wan contributed to drafting the manuscript. All authors have read and approved the final submitted manuscript.

\section{Compliance with ethical standards}

Conflict of interest All authors declare that they have no conflict of interest.

Open Access This article is licensed under a Creative Commons Attribution 4.0 International License, which permits use, sharing, adaptation, distribution and reproduction in any medium or format, as long as you give appropriate credit to the original author(s) and the source, provide a link to the Creative Commons licence, and indicate if changes were made. The images or other third party material in this article are included in the article's Creative Commons licence, unless indicated otherwise in a credit line to the material. If material is not included in the article's Creative Commons licence and your intended use is not permitted by statutory regulation or exceeds the permitted use, you will need to obtain permission directly from the copyright holder. To view a copy of this licence, visit http://creativecommons.org/licenses/by/4.0/.

\section{References}

1. D. Wu, C. Duan, L. Chen, S. Chen, Efficacy and safety of different doses of cytarabine in consolidation therapy for adult acute myeloid leukemia patients: A network meta-analysis. Sci. Rep. 7, 9509 (2017)

2. M. Stelljes, U. Krug, D.W. Beelen, J. Braess, M.C. Sauerland, A. Heinecke, S. Ligges, T. Sauer, P. Tschanter, G.B. Thoennissen, B. Berning, H.J. Kolb, A. Reichle, E. Holler, R. Schwerdtfeger, R. Arnold, C. Scheid, C. Muller-Tidow, B.J. Woermann, W. Hiddemann, W.E. Berdel, T. Buchner, Allogeneic transplantation versus chemotherapy as postremission therapy for acute myeloid leukemia: A prospective matched pairs analysis. J. Clin. Oncol. 32, 288-296 (2014)

3. F. Ferrara, G. Barosi, A. Venditti, E. Angelucci, M. Gobbi, F. Pane, P. Tosi, P. Zinzani, S. Tura, Consensus-based definition of unfitness to intensive and non-intensive chemotherapy in acute myeloid leukemia: A project of SIE, SIES and GITMO group on a new tool for therapy decision making. Leukemia 27, 997-999 (2013)

4. S.K. Tasian, Acute myeloid leukemia chimeric antigen receptor Tcell immunotherapy: How far up the road have we traveled? Ther. Adv. Hematol. 9, 135-148 (2018)

5. G.L. Shah, C.H. Moskowitz, Checkpoint inhibition in lymphoma. Clin. Adv. Hematol. Oncol. 16, 45-55 (2018)

6. F. McClanahan, B. Hanna, S. Miller, A.J. Clear, P. Lichter, J.G. Gribben, M. Seiffert, PD-L1 checkpoint blockade prevents immune dysfunction and leukemia development in a mouse model of chronic lymphocytic leukemia. Blood 126, 203-211 (2015)

7. M. Wierz, S. Pierson, L. Guyonnet, E. Viry, A. Lequeux, A. Oudin, S.P. Niclou, M. Ollert, G. Berchem, B. Janji, C. Guerin, J. Paggetti, E. Moussay, Dual PD1/LAG3 immune checkpoint blockade limits tumor development in a murine model of chronic lymphocytic leukemia. Blood 131, 1617-1621 (2018)

8. M. Pascual, M. Mena-Varas, E.F. Robles, M.J. Garcia-Barchino, C. Panizo, S. Hervas-Stubbs, D. Alignani, A. Sagardoy, J.I. MartinezFerrandis, K.L. Bunting, S. Meier, X. Sagaert, D. Bagnara, E. Guruceaga, O. Blanco, J. Celay, A. Martinez-Baztan, N. Casares, J.J. Lasarte, T. MacCarthy, A. Melnick, J.A. Martinez-Climent, S. Roa, PD-1/PD-L1 immune checkpoint and p53 loss facilitate tumor progression in activated B-cell diffuse large B-cell lymphomas. Blood 133, 2401-2412 (2019)

9. A. Ghahremanloo, A. Soltani, S.M.S. Modaresi, S.I. Hashemy, Recent advances in the clinical development of immune checkpoint blockade therapy. Cell. Oncol. 42, 609-626 (2019)

10. D.A. Tesfatsion, Dendritic cell vaccine against leukemia: Advances and perspectives. Immunotherapy 6, 485-496 (2014)

11. S.A. Fisher, A. Cleaver, D.D. Lakhiani, A. Khong, T. Connor, B. Wylie, W.J. Lesterhuis, B.W. Robinson, R.A. Lake, Neoadjuvant anti-tumor vaccination prior to surgery enhances survival. J. Transl. Med. 12, 245 (2014)

12. S. Hao, T. Moyana, J. Xiang, Review: Cancer immunotherapy by exosome-based vaccines. Cancer Biother. Radiopharm. 22, 692-703 (2007) 
13. F. Andre, N. Chaput, N.E. Schartz, C. Flament, N. Aubert, J. Bernard, F. Lemonnier, G. Raposo, B. Escudier, D.H. Hsu, T. Tursz, S. Amigorena, E. Angevin, L. Zitvogel, Exosomes as potent cell-free peptide-based vaccine. I Dendritic cell-derived exosomes transfer functional MHC class I/peptide complexes to dendritic cells. J. Immunol. 172, 2126-2136 (2004)

14. F. Andre, N.E. Schartz, N. Chaput, C. Flament, G. Raposo, S. Amigorena, E. Angevin, L. Zitvogel, Tumor-derived exosomes: A new source of tumor rejection antigens. Vaccine. 20(Suppl 4), A28-A31 (2002)

15. Y. Yao, L. Chen, W. Wei, X. Deng, L. Ma, S. Hao, Tumor cellderived exosome-targeted dendritic cells stimulate stronger CD8+ CTL responses and antitumor immunities. Biochem. Biophys. Res. Commun. 436, 60-65 (2013)

16. V. Sundararajan, F.H. Sarkar, T.S. Ramasamy, The versatile role of exosomes in cancer progression: Diagnostic and therapeutic implications. Cell. Oncol. 41, 223-252 (2018)

17. Y. Yao, C. Wang, W. Wei, C. Shen, X. Deng, L. Chen, L. Ma, S. Hao, Dendritic cells pulsed with leukemia cell-derived exosomes more efficiently induce antileukemic immunities. PLoS One 9, e91463 (2014)

18. C. Shen, S.G. Hao, C.X. Zhao, J. Zhu, C. Wang, Antileukaemia immunity: Effect of exosomes against NB4 acute promyelocytic leukaemia cells. J. Int Med. Res. 39, 740-747 (2011)

19. M. Schmitt, L. Li, K. Giannopoulos, J. Chen, C. Brunner, T. Barth, A. Schmitt, M. Wiesneth, K. Dohner, H. Dohner, J. Greiner, Chronic myeloid leukemia cells express tumor-associated antigens eliciting specific CD8+ T-cell responses and are lacking costimulatory molecules. Exp. Hematol. 34, 1709-1719 (2006)

20. L.E. Van den Hove, S.W. Van Gool, P. Vandenberghe, M. Bakkus, K. Thielemans, M.A. Boogaerts, J.L. Ceuppens, CD40 triggering of chronic lymphocytic leukemia B cells results in efficient alloantigen presentation and cytotoxic $\mathrm{T}$ lymphocyte induction by upregulation of CD80 and CD86 costimulatory molecules. Leukemia 11, 572-580 (1997)

21. C. Palena, M. Zhu, J. Schlom, K.Y. Tsang, Human B cells that hyperexpress a triad of costimulatory molecules via avipox-vector infection: An alternative source of efficient antigen-presenting cells. Blood 104, 192-199 (2004)

22. C. Palena, K.A. Foon, D. Panicali, A.G. Yafal, J. Chinsangaram, J.W. Hodge, J. Schlom, K.Y. Tsang, Potential approach to immunotherapy of chronic lymphocytic leukemia (CLL): Enhanced immunogenicity of CLL cells via infection with vectors encoding for multiple costimulatory molecules. Blood 106, 3515-3523 (2005)

23. L. Chen, S. Ashe, W.A. Brady, I. Hellstrom, K.E. Hellstrom, J.A. Ledbetter, P. McGowan, P.S. Linsley, Costimulation of antitumor immunity by the B7 counterreceptor for the T lymphocyte molecules CD28 and CTLA-4. Cell 71, 1093-1102 (1992)

24. X. Ke, L. Jia, J. Wang, D. Wang, Transfection of B7-1 cDNA empowers antigen presentation of blood malignant cells for activation of anti-tumor T cells. Chin. Med. J. 116, 78-84 (2003)

25. J. Hong, X.D. Gu, J.B. Xiang, Z. Zhang, Y.W. Zang, Q.H. Zhang, S.G. Qian, Z.Y. Chen, Recipient dendritic cells modified by RNA interference targeting CD80 and CD86 elicit T cell hyporesponsiveness via enhanced T cell apoptosis. Chin. Med. J. 126, 2139-2144 (2013)

26. H.G. Lamparski, A. Metha-Damani, J.Y. Yao, S. Patel, D.H. Hsu, C. Ruegg, J.B. Le Pecq, Production and characterization of clinical grade exosomes derived from dendritic cells. J. Immunol. Methods 270, 211-226 (2002)

27. J. Wang, L. Wang, Z. Lin, L. Tao, M. Chen, More efficient induction of antitumor T cell immunity by exosomes from CD40L genemodified lung tumor cells. Mol. Med. Rep. 9, 125-131 (2014)
28. F. Huang, J. Wan, W. Hu, S. Hao, Enhancement of anti-leukemia immunity by leukemia-derived Exosomes via downregulation of TGF-beta1 expression. Cell. Physiol. Biochem. 44, 240-254 (2017)

29. S. Hao, O. Bai, F. Li, J. Yuan, S. Laferte, J. Xiang, Mature dendritic cells pulsed with exosomes stimulate efficient cytotoxic Tlymphocyte responses and antitumour immunity. Immunology 120, 90-102 (2007)

30. S. Dai, D. Wei, Z. Wu, X. Zhou, X. Wei, H. Huang, G. Li, Phase I clinical trial of autologous ascites-derived exosomes combined with GM-CSF for colorectal cancer. Mol. Ther.: J. Am. Soc. Gene. Ther. 16, 782-790 (2008)

31. F. Huang, J. Wan, S. Hao, X. Deng, L. Chen, L. Ma, TGF-beta1silenced leukemia cell-derived exosomes target dendritic cells to induce potent anti-leukemic immunity in a mouse model. Cancer Immunol. Immunother. 66, 1321-1331 (2017)

32. W.G. Wierda, M.J. Cantwell, S.J. Woods, L.Z. Rassenti, C.E. Prussak, T.J. Kipps, CD40-ligand (CD154) gene therapy for chronic lymphocytic leukemia. Blood 96, 2917-2924 (2000)

33. J.A. Wolos, F.R. Davey, B lymphocyte function in B cell chronic lymphocytic leukaemia. Br. J. Haematol. 49, 395-403 (1981)

34. A.M. Krackhardt, S. Harig, M. Witzens, R. Broderick, P. Barrett, J.G. Gribben, T-cell responses against chronic lymphocytic leukemia cells: Implications for immunotherapy. Blood 100, 167-173 (2002)

35. E. Biagi, G. Dotti, E. Yvon, E. Lee, M. Pule, S. Vigouroux, S. Gottschalk, U. Popat, R. Rousseau, M. Brenner, Molecular transfer of CD40 and OX40 ligands to leukemic human B cells induces expansion of autologous tumor-reactive cytotoxic T lymphocytes. Blood 105, 2436-2442 (2005)

36. S.E. Townsend, J.P. Allison, Tumor rejection after direct costimulation of CD8+ T cells by B7-transfected melanoma cells. Science 259, 368-370 (1993)

37. J.W. Hodge, H. Sabzevari, A.G. Yafal, L. Gritz, M.G. Lorenz, J. Schlom, A triad of costimulatory molecules synergize to amplify Tcell activation. Cancer Res. 59, 5800-5807 (1999)

38. J.W. Hodge, A.N. Rad, D.W. Grosenbach, H. Sabzevari, A.G. Yafal, L. Gritz, J. Schlom, Enhanced activation of T cells by dendritic cells engineered to hyperexpress a triad of costimulatory molecules. J. Natl. Cancer Inst. 92, 1228-1239 (2000)

39. S.E. Church, S.M. Jensen, P.A. Antony, N.P. Restifo, B.A. Fox, Tumor-specific CD4+ T cells maintain effector and memory tumorspecific CD8+ T cells. Eur. J. Immunol. 44, 69-79 (2014)

40. R.H. Nanjundappa, R. Wang, Y. Xie, C.S. Umeshappa, J. Xiang, Novel CD8+ T cell-based vaccine stimulates Gp120-specific CTL responses leading to therapeutic and long-term immunity in transgenic HLA-A2 mice. Vaccine 30, 3519-3525 (2012)

41. D. Xia, S. Hao, J. Xiang, CD8+ cytotoxic T-APC stimulate central memory CD8+ T cell responses via acquired peptide-MHC class I complexes and CD80 costimulation, and IL-2 secretion. J Immunol. 177, 2976-2984 (2006)

42. C. Admyre, S.M. Johansson, S. Paulie, S. Gabrielsson, Direct exosome stimulation of peripheral human $\mathrm{T}$ cells detected by ELISPOT. Eur. J. Immunol. 36, 1772-1781 (2006)

43. C.Y. Chiang, Y.J. Chen, C.C. Wu, S.J. Liu, C.H. Leng, H.W. Chen, Efficient uptake of recombinant lipidated Survivin by antigenpresenting cells initiates antigen cross-presentation and antitumor immunity. Front. Immunol. 9, 822 (2018)

44. T. El-Murr, A. Patel, C. Sedlak, B. D'Souza-Lobo, Evaluating dendritic cells as an in vitro screening tool for immunotherapeutic formulations. J. Immunol. Methods 459, 55-62 (2018)

45. X. Gu, U. Erb, M.W. Buchler, M. Zoller, Improved vaccine efficacy of tumor exosome compared to tumor lysate loaded dendritic cells in mice. Int. J. Cancer 136, E74-E84 (2015) 
46. K. Palucka, H. Ueno, J. Fay, J. Banchereau, Dendritic cells and immunity against cancer. J. Intern. Med. 269, 64-73 (2011)

47. S. Hao, O. Bai, J. Yuan, M. Qureshi, J. Xiang, Dendritic cellderived exosomes stimulate stronger CD8+ CTL responses and antitumor immunity than tumor cell-derived exosomes. Cell. Mol. Immunol. 3, 205-211 (2006)
48. M.M. Rangel-Sosa, E. Aguilar-Cordova, A. Rojas-Martinez, Immunotherapy and gene therapy as novel treatments for cancer. Colomb. Med. (Cali). 48, 138-147 (2017)

Publisher's note Springer Nature remains neutral with regard to jurisdictional claims in published maps and institutional affiliations. 